\title{
Altered expression of imprinted genes in Wilms tumors
}

\author{
JOCHEN HUBERTUS ${ }^{1}$, MARTIN LACHER ${ }^{1}$, MARIETTA ROTTENKOLBER ${ }^{2}$, JOSEF MÜLLER-HÖCKER $^{3}$, \\ MICHAEL BERGER $^{1}$, MAXIMILIAN STEHR ${ }^{1}$, DIETRICH VON SCHWEINITZ ${ }^{1}$ and ROLAND KAPPLER ${ }^{1}$ \\ ${ }^{1}$ Department of Pediatric Surgery, Research Laboratories, Ludwig-Maximilians-University of Munich, \\ Lindwurmstrasse 2a, D-80337 Munich; ${ }^{2}$ Institute of Medical Informatics, Biometry, and Epidemiology, \\ Ludwig-Maximilians-University of Munich, Marchioninistrasse 15, D-81377 Munich; ${ }^{3}$ Institute of Pathology, \\ Ludwig-Maximilians-University Munich, Thalkirchner Strasse 36, D-80337 Munich, Germany
}

Received August 27, 2010; Accepted November 5, 2010

DOI: $10.3892 / o r .2010 .1113$

\begin{abstract}
Overexpression of insulin-like growth factor 2 (IGF2), an imprinted gene located on chromosome 11p15, has been reported as a characteristic feature in various embryonal tumors, including Wilms tumor (WT). Recent studies specified loss of imprinting (LOI) in a differential methylated region (DMR) of the IGF2/H19 cluster or loss of heterozygosity (LOH), respectively, uniparental disomy (UPD) being responsible for this overexpression. However, the role of other imprinted genes in the genesis of WT is still unknown. In the current study, we analyzed transcriptional activity of the imprinted genes IGF2, H19, NNAT, DLK1, RTL1, MEG3, and MEST as well as the methylation status of the DMR of the IGF2/H19 cluster in a panel of 32 WTs. Except for H19, we detected massive overexpression of all genes in the majority of WTs compared to normal renal tissue, which was most prominent for the paternally expressed genes $I G F 2$, NNAT, and MEST. Alterations of the H19DMR were found in two-thirds of the WTs. Moreover, we have seen a strong correlation between the transcriptional activity of $I G F 2$, NNAT and MEST and LOI/LOH of H19DMR, which was inverse for H19. Expression of DLK1, RTL1 and MEG3 does not correlate with LOI/LOH of H19DMR. Altogether, our findings suggest that over-expression of imprinted genes is common in WTs and correlates at least for some imprinted genes with LOI of H19DMR. Thus, it may be speculated that alterations of the DNA modification machinery drive erroneous setting of methylation marks in imprinting regions throughout the genome, which leads to the concomitant activation of imprinted genes in blastomagenesis.
\end{abstract}

Correspondence to: Dr Jochen Hubertus, Department of Pediatric Surgery, Research Laboratories, Ludwig-Maximilians-University of Munich, Lindwurmstrasse 2a, D-80337 Munich, Germany

E-mail: jochen.hubertus@med.uni-muenchen.de

Key words: methylation, imprinting, insulin-like growth factor 2, nephroblastoma

\section{Introduction}

Wilms tumor (WT), or nephroblastoma, accounts for $6 \%$ of all solid tumors in children less than 15 years of age and has an incidence of 13/100.000 (1). These malignant embryonal tumors are thought to develop from precursor cells at an early stage of metanephric differentiation (2). Certain characteristic genes such as PAX2, EYA1, HBF2, HOXA1, SIX1, MOX1, and SALL2 are known to be overexpressed during this stage of renal differentiation, and the transcriptional activity of these genes in WT is similar (2).

In adults, most tumors arise from structural mutations of genes with tumor suppressor function (3). However, alterations of tumor suppressor genes such as WT1, WTX, and CTNNB1 are seen in $<30 \%$ of WTs (4). Moreover, mutations of these genes do not correlate with clinical parameters such as tumor progression, risk of relapse and/or poor outcome in WTs (4). Therefore, embryonal tumors seem not to originate from an accumulation of gene defects (4), suggesting that other factors may play a role in tumorigenesis.

Among these factors, overexpression of insulin-like growth factor 2 (IGF2) has been reported as a common finding in both WTs and other embryonal tumors (4-8). IGF2 belongs to a group of genes called imprinted genes, which are expressed in a parent-of-origin-specific manner. Transcription is regulated by two major mechanisms, including DNA methylation and histone modifications $(9,10)$. Histone modifications inhibit transcription by DNA condensation. DNA methylation occurs in cytosine-phosphate-guanine $(\mathrm{CpG})$ rich sites of the genome, which act as gene promoters. Methylation of $\mathrm{CpGs}$ in so-called differential methylated regions (DMR) serves as a regulatory mechanism of imprinted genes (11). In the majority of cases, the DMR controls a selection of clustered imprinted genes. Each cluster contains a subset of maternally (MEG) and paternally expressed genes (PEG) (12). Whether the imprinted gene is activated or deactivated is determined by parental specific methylation of the DMR.

The best-investigated imprinted gene so far is $I G F 2$, which is part of the IGF2/H19-cluster (H19DMR). Its role has been studied in many embryonal and adult tumors $(5,7,13)$. Under physiologic conditions the H19DMR is methylated on the paternal allele that expresses $I G F 2$ (14). Since both alleles are methylated in case of loss of imprinting (LOI) or loss of 
heterozygosity $(\mathrm{LOH}), I G F 2$ is transcribed from both alleles resulting in $I G F 2$ overexpression and consecutive tumor formation (12). However, it is unknown whether overexpression of $I G F 2$ is independent of other imprinted genes such as neuronatin (NNAT) or delta-like 1 homolog (DLK1), which may also be key players of tumorigenesis $(2,15)$. Therefore, the aim of this study was to assess transcriptional activity of imprinted genes other than IGF2 in WTs and to correlate expression data to the methylation status of H19DMR.

\section{Materials and methods}

Patients. Thirty-two native WT specimens were investigated from patients undergoing surgical tumor resection in our department. The median age at time of surgery was 41 months (range 4 months to 17 years) with a sex ratio of 1:1.4 (f:m). Twenty-nine patients $(90 \%)$ underwent neoadjuvant chemotherapy according to the International Society of Pediatric Oncology (SIOP) protocol (16). Six patients (19\%) were found to have bilateral WTs. The control group $(n=9)$ consisted of renal tissue from the healthy part of the resected specimen after tumor nephrectomy. The median age of the control group was 39 months (range: 19 month to 14 years) with a gender ratio of 1:1.25 (f:m). Histological classification of the samples was performed by a trained pathologist (J.M.-H.). The study was approved by the local ethics committee of the Ludwig-Maximilians-University of Munich. Written consent was obtained from all parents.

Real-time reverse transcription-PCR (RT-PCR). Tri Reagent ${ }^{\circledR}$ was used for isolation of total RNA from native samples. Total RNA was depleted from DNA and subsequently purified using DNase set and RNeasy mini kit, respectively (Qiagen, Hilden, Germany). Reverse transcription of total RNA was performed using random hexamers (Roche Diagnostics, Penzberg, Germany) and SuperScript II reverse transcriptase (Invitrogen, Carlsbad, CA, USA). Intron-spanning primers were designed for the human genes IGF2, H19, NNAT, $D L K 1$, mesoderm specific transcript homolog (MEST), retrotransposon-like 1 (RTL1) and maternally expressed gene 3 (MEG3) using Primer Express ${ }^{\circledR}$ v2.0 (Applied Biosystems, Foster City, CA, USA) based on the sequence information contained in the Ensembl Database. Primers are listed in detail in Table I. PCR amplifications were carried out with $40 \mathrm{ng}$ of cDNA, $500 \mathrm{nM}$ forward and reverse primer and iTaq SYBR Green Supermix (Bio-Rad Laboratories, Hercules, CA, USA) in a final volume of $20 \mu \mathrm{l}$. PCR reactions were run for 40 cycles consisting of $15 \mathrm{sec}$ denaturation at $95^{\circ} \mathrm{C}$, primer annealing for $15 \mathrm{sec}$ at $55^{\circ} \mathrm{C}$, and extension for $30 \mathrm{sec}$ at $72^{\circ} \mathrm{C}$ on a Mastercycler Realplex ${ }^{2}$ cycler (Eppendorf, Hamburg, Germany). All PCR reactions were prepared in doublets and standardized to the reference gene TATA-box-binding-protein (TBP). Level of expression was calculated according to the mathematical model of Pfaffl et al (17).

Methylation status in the DMR of the IGF2/H19 cluster. Determination of methylation status was performed using a quantitative real-time PCR-based method described by Fukuzawa et al (14). This assay allows for the discrimination
Table I. Overview of the primers used for quantitative RT-PCR gene expression analysis and the H19DMR methylation assay.

\begin{tabular}{|c|c|}
\hline Primers & Sequence $\left(5^{\prime} \rightarrow 3^{\prime}\right)$ \\
\hline$N N A T$ fwd & CGGCTGGTACATCTTCCGC \\
\hline$N N A T \_r v$ & TGTCCCTGGAGGATTTCGAAA \\
\hline$I G F 2 \_f w d$ & CCCGCTGGGCCAATCT \\
\hline$I G F 2 \_r v$ & GAGTCTGGTTTTGATGCCACC \\
\hline H19_fwd & CTCACCCACCGCAATTCATT \\
\hline H19_rv & CGTGCCGGAGCTGCC \\
\hline$D L K 1 \_f w d$ & GCAACCCCCAAAATGGATTC \\
\hline$D L K 1 \_r v$ & GAGGTCACGCACTGGTCACA \\
\hline$R T L 1$ fwd & GCATTGCCCTAGAGAGGCAC \\
\hline RTL1_rv & GCTTCCTTCGGGTTAAACACG \\
\hline$M E S T$ fwd & TCCCCTGCCCTTCACTCAT \\
\hline$M E S T \_r v$ & CAACCACACCCACAGAGTCTTG \\
\hline$M E G 3 \_$fwd & ССTCTCCATGCTGAGCTGCT \\
\hline MEG3_rv & TGTTGGTGGGATCCAGGAAA \\
\hline H19DMR_fwd & GGCCCTAGTGTGAAACCCTTCTCG \\
\hline H19DMR_rv & CAGGCGGTGAGACCGAAGGA \\
\hline$K v D M R 1 D M R \_f w d$ & CCCGCTGGGCCAATCT \\
\hline$K v D M R 1 D M R \_r v$ & GAGTCTGGTTTTGATGCCACC \\
\hline
\end{tabular}

fwd, forward; rv, reverse.

of loss of heterozygosity ( $\mathrm{LOH})$, retention of imprinting (ROI) and loss of imprinting (LOI) at the IGF2/H19 locus by measuring the extent of methylation in two different DMRs on chromosome $11 \mathrm{p} 15$, namely the H19DMR and the KvDMRI. In brief, genomic DNA was extracted from native samples using standard procedures. DNA (600 ng) was separated into three vials and digested with either RsaI (10 units), RsaI (10 units) plus the methylation-sensitive restriction enzyme HpaII (10 units), or MspI (10 units) as a control for $4 \mathrm{~h}$ at $37^{\circ} \mathrm{C}$. Restricted DNA was subsequently amplified with primers (Table I) specific for the differential methylated region upstream of $H 19$ gene and the KvDMR1 region $(18,19)$. Template DNA was quantified in a $20 \mu 1$ reaction containing $10 \mu \mathrm{l} \mathrm{SYBR}$ Green ${ }^{\circledR}, 25 \mathrm{ng}$ template, $1 \mu \mathrm{M}$ forward and $1 \mu \mathrm{M}$ reverse primer by use of quantitative PCR on a Mastercycler Realplex ${ }^{2}$ cycler (Eppendorf). The amount of amplifiable template remaining after RsaI and HpaII digestion was compared with that remaining after the single RsaI digest, allowing the percentage of methylation to be estimated at a specific $\mathrm{CpG}$ site. The RsaI + MspI digest was used as a control for complete digestion. Percentage of methylated (undigested) DNA was calculated by dividing the amount of DNA amplified from the RsaI/HpaII digested sample by that from the control RsaI digest.

Statistics. Statistical analysis was made with SPSS ${ }^{\circledR}$ v17.0. An explorative analysis was made without corrections of p-values for multiple testing. Mann-Whitney U test was used for comparison of gene expression data and methylation status. Relationship between two expression levels has been measured by Spearman's rank correlation coefficient $\left(r_{s}\right)$. 
$\mathbf{A}$

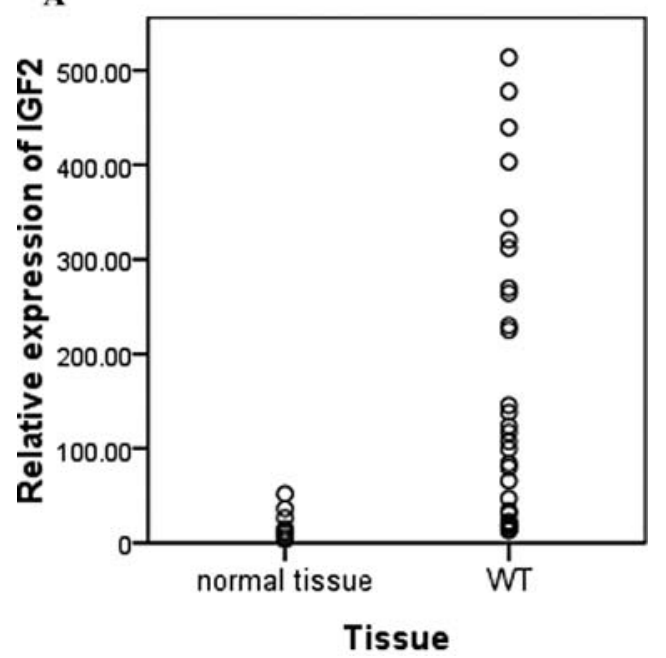

C

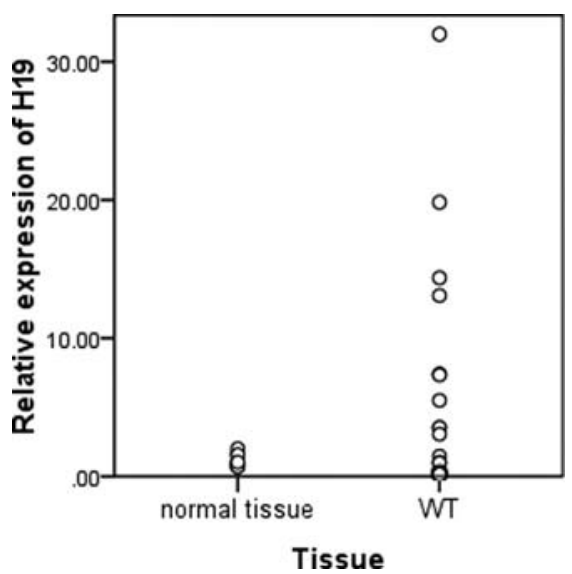

B

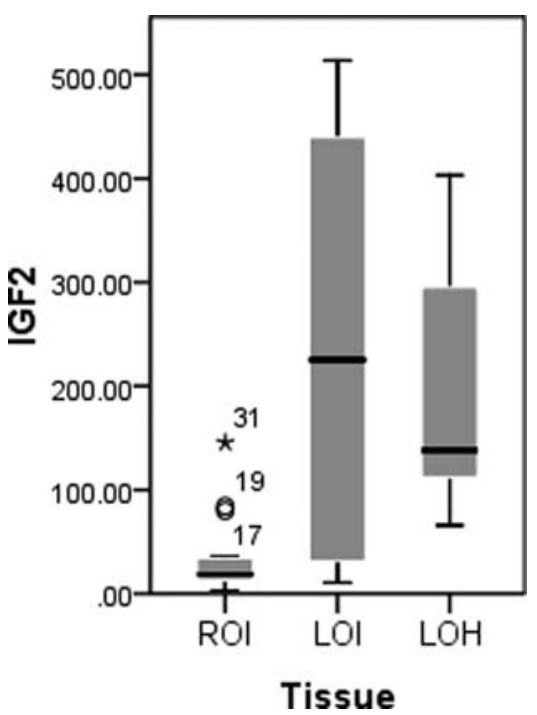

D

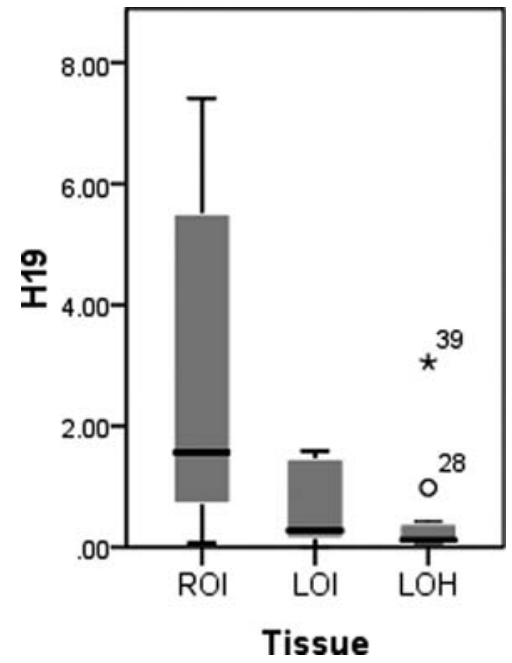

Figure 1. Expression analysis of the imprinted genes $I G F 2$ (A) and $H 19$ (C) in normal renal and tumor tissues (WT), as determined by real-time PCR. Gene expression is calculated in relation to the housekeeping gene TBP. Correlation of gene expression and methylation status of $H 19 D M R$. Boxplots display distribution of TBP-normalized expression levels for IGF2 (B) and $H 19$ (D) of tumor cases in correlation to the methylation status of $H 19 D M R$.

\section{Results}

Expression of imprinted genes in Wilms tumor. To screen for altered expression of imprinted genes in WT, we selected seven different genes with varying functions (Table II). NNAT, $I G F 2$, and $M E S T$ are involved in development and growth (20-23), whereas the non-coding RNA of H19 and MEG3 exert regulatory function on the adjacent imprinting clusters (24,25). DLK1 and RTL1 are responsible for neuroendocrine differentiation and development of the placenta $(15,20,21)$. Five of seven genes are paternally expressed (IGF2, NNAT, MEST, DLK1, and RTL1), whereas MEG3 and H19 are maternally expressed. Except for NNAT, all are regulated in certain imprinting clusters (15).

We investigated transcriptional activity of these genes in 32 WTs and compared their expression level with normal renal tissue (Figs. 1-3). Statistical analyses revealed that $I G F 2$, DLK1, RTL1, MEG3, and NNAT were significantly overexpressed compared to normal renal tissue $(\mathrm{p}<0.01)$. Differences in expression were not so distinct, but significant, also for MEST ( $\mathrm{p}=0.02)$. However, expression of H19 was not significantly different from those in normal tissue $(\mathrm{p}=0.25)$.

Next, expression level of the different genes was correlated with each other using the Spearman's rank correlation coefficient (Table III). We found that expression of IGF2 is negatively associated with that of $H 19\left(\mathrm{p}=0.031, r_{s}=-0.39\right)$, corroborating earlier findings that $I G F 2$ is negatively regulated by $H 19$ (12). Furthermore, elevated expression of IGF2 was significantly correlated with increased levels of NNAT and $\operatorname{MEST}\left(\mathrm{p}<0.01, r_{s}=0.60\right)$. Accordingly, high expression levels of NNAT and MEST were linked as well with high significance $\left(\mathrm{p}<0.01, r_{s}=0.78\right)$.

However, DLK1, MEG3, and RTL1, members of the $D L K 1 / G T L 2$ imprinting cluster were not correlated with genes outside this cluster ( $\mathrm{p}>0.05)$ (Table III). In addition, there was no correlation between RTL1 and MEG3 ( $>0.05$, $r_{s}=0.95$ ), and expression level of $D L K 1$ was independent of the other two $(\mathrm{p}>0.05)$. Especially in the case of $D L K 1$ and $M E G 3$, inverse regulation was not evident $\left(r_{s}=0.23\right)$. 
Table II. Characteristics of imprinted genes analyzed in Wilms tumors of the current study.

\begin{tabular}{|c|c|c|c|c|}
\hline Gene & Location & Function & Expressed allele & Imprinting cluster \\
\hline$I G F 2$ & $11 \mathrm{p} 15$ & Involved in development and growth & $\mathrm{P}$ & $I G F 2 / H 19$ \\
\hline$H 19$ & $11 \mathrm{p} 15$ & Non-coding RNA, functions as a tumor suppressor & M & $I G F 2 / H 19$ \\
\hline$D L K 1$ & $14 \mathrm{q} 32$ & Plays a role in neuroendocrine differentiation & $\mathrm{P}$ & $D L K 1 / G T L 2$ \\
\hline RTL1 & $14 q 32$ & $\begin{array}{l}\text { Maintenance of feto-maternal interface } \\
\text { and for development of the placenta }\end{array}$ & $\mathrm{P}$ & $D L K 1 / G T L 2$ \\
\hline MEG3 & $14 q 32$ & Non-coding RNA, regulates the $D L K 1 / G T L 2$ locus & M & $D L K 1 / G T L 2$ \\
\hline NNAT & $20 q 11$ & Regulation of ion channels during brain development & $\mathrm{P}$ & No \\
\hline MEST & $7 q 32$ & Plays a role in development & $\mathrm{P}$ & CPA4/MEST \\
\hline
\end{tabular}

P, paternally expressed; M, maternally expressed.

Table III. Dependency of gene expression using Spearman's rank correlation.

\begin{tabular}{|c|c|c|c|c|c|c|c|}
\hline & & NNAT & $I G F 2$ & $D L K 1$ & H19 & RTL1 & MEG3 \\
\hline MEST & $\begin{array}{c}r_{s} \\
\text { p-value }\end{array}$ & $\begin{array}{r}0.78 \\
<\mathbf{0 . 0 1}\end{array}$ & $\begin{array}{r}0.60 \\
<0.01\end{array}$ & $\begin{array}{r}0.08 \\
>0.05\end{array}$ & $\begin{array}{l}-0.19 \\
>0.05\end{array}$ & $\begin{array}{r}0.08 \\
>0.05\end{array}$ & $\begin{array}{l}-0.04 \\
>0.05\end{array}$ \\
\hline NNAT & $\begin{array}{c}r_{s} \\
\text { p-value }\end{array}$ & & $\begin{array}{r}0.60 \\
<\mathbf{0 . 0 1}\end{array}$ & $\begin{array}{l}0.40 \\
\mathbf{0 . 0 3}\end{array}$ & $\begin{array}{r}-0.13 \\
>0.05\end{array}$ & $\begin{array}{r}0.09 \\
>0.05\end{array}$ & $\begin{array}{r}0.04 \\
>0.05\end{array}$ \\
\hline$I G F 2$ & $\begin{array}{c}r_{s} \\
\text { p-value }\end{array}$ & & & $\begin{array}{r}0.30 \\
>0.05\end{array}$ & $\begin{array}{c}-0.39 \\
\mathbf{0 . 0 3 1}\end{array}$ & $\begin{array}{r}-0.09 \\
>0.05\end{array}$ & $\begin{array}{l}-0.15 \\
>0.05\end{array}$ \\
\hline$D L K 1$ & $\begin{array}{c}r_{s} \\
\text { p-value }\end{array}$ & & & & $\begin{array}{l}-0.13 \\
>0.05\end{array}$ & $\begin{array}{r}0.21 \\
>0.05\end{array}$ & $\begin{array}{r}0.23 \\
>0.05\end{array}$ \\
\hline H19 & $\begin{array}{c}r_{s} \\
\text { p-value }\end{array}$ & & & & & $\begin{array}{r}0.02 \\
>0.05\end{array}$ & $\begin{array}{r}0.08 \\
>0.05\end{array}$ \\
\hline RTLI & $\begin{array}{c}r_{s} \\
\text { p-value }\end{array}$ & & & & & & $\begin{array}{r}0.95 \\
>0.05\end{array}$ \\
\hline
\end{tabular}

Positive correlation coefficient $\left(\mathrm{r}_{\mathrm{s}}\right)$ stands for overexpression in both examined genes, a negative one means a low expression level for one gene, whereas the other is overexpressed.

Correlation of H19DMR imprinting status and gene expression level of imprinted genes. Investigating the methylation status of H19DMR revealed a balanced distribution of LOI, ROI and LOH for WT samples. Two-thirds had alterations in H19DMR methylation. Among these samples, 11 had LOI and another $11 \mathrm{LOH}$. ROI was evident for the remaining 10 tissues. Interestingly, two samples of the nine normal renal tissues had LOI in their H19DMR, while the other ones had ROI.

Statistical analyses revealed a significant correlation of LOI of the H19DMR with an overexpression of IGF2 $(\mathrm{p}<0.01)$ and suppression of $H 19(\mathrm{p}=0.01)$. Interestingly, transcriptional behavior of MEST $(\mathrm{p}<0.01)$ and $N N A T$ $(\mathrm{p}<0.01)$ were correlated with the methylation status of H19DMR as well (Fig. 3). Although genes of the DLK1/GTL2 locus were overexpressed, expression levels of $D L K 1, R T L 1$ and MEG3 (all p>0.05) were not correlated with H19DMR methylation status (Fig. 2).

\section{Discussion}

This study reports on the expression profiling of several imprinted genes in a large collection of WTs. Seven genes were chosen to cover different aspects with regard to parental origin, organization in an imprinting cluster, function, and genomic localization (Table II). We observed a significant overexpression of the imprinted genes $I G F 2$, DLK1, RTL1, $M E G 3$, and NNAT, and to a lesser extent of MEST, when compared to not affected renal tissue. These data indicate a general activation of imprinted genes in WTs, except for the non-coding H19. Our findings are in line with a previous study using comparative expression analyses of native WT, 


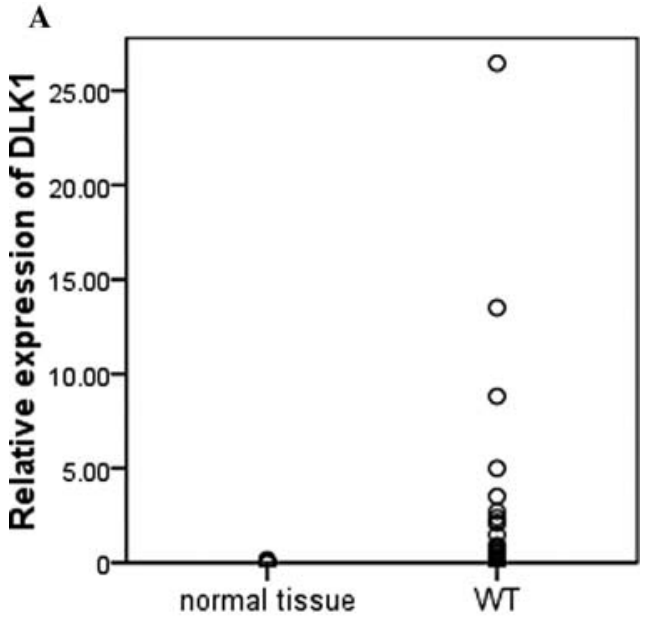

Tissue

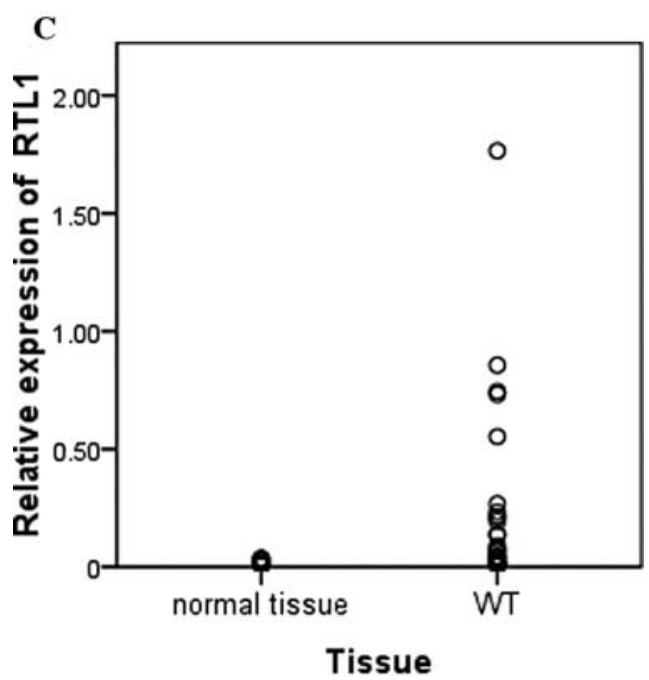

$\mathbf{E}$

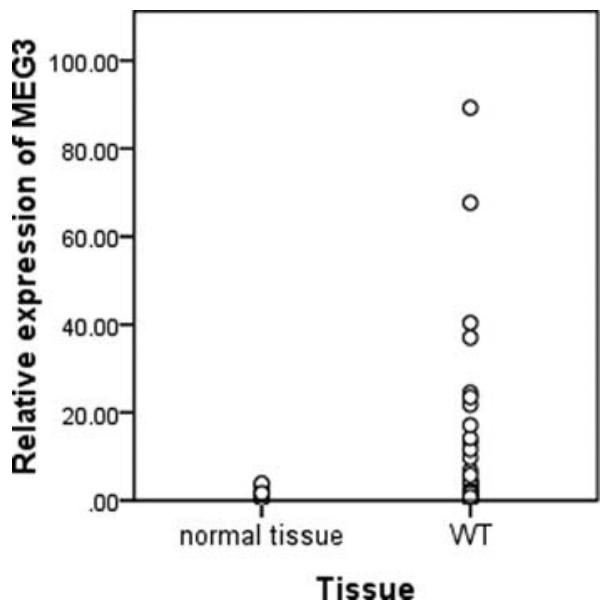

B

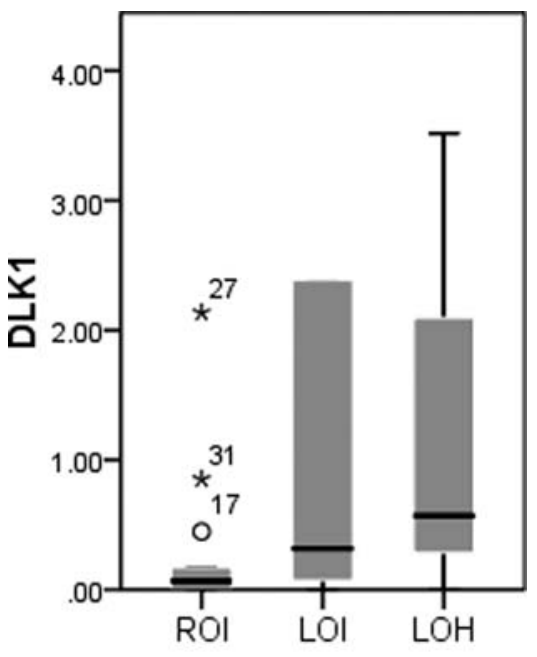

Tissue

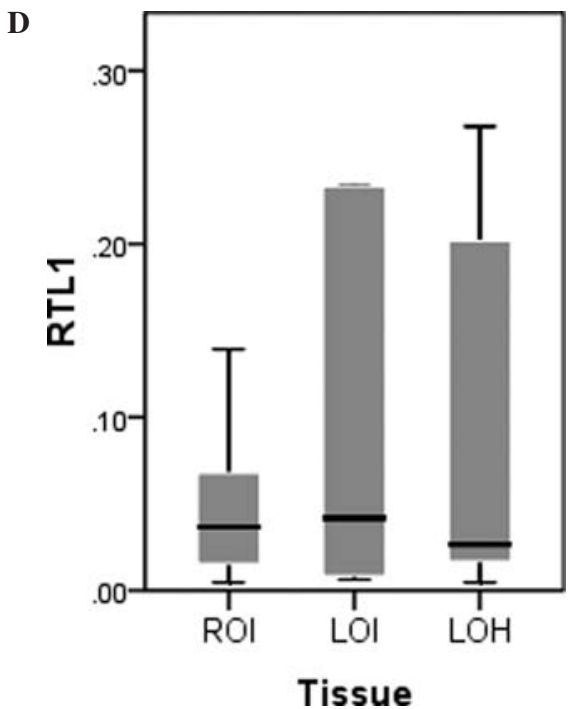

F

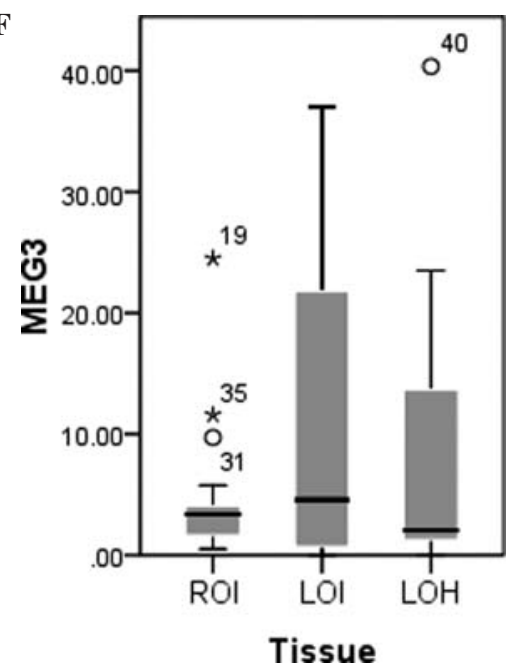

Figure 2. Expression analysis of the imprinted genes $D L K 1$ (A), RTL1 (C), and MEG3 (E) in normal renal and tumor tissues (WT), as determined by real-time PCR. Gene expression is calculated in relation to the housekeeping gene TBP. Correlation of gene expression and methylation status of $H 19 D M R$. Boxplots display distribution of TBP-normalized expression levels $D L K 1$ (B), RTL1 (D), and MEG3 (F) of tumor cases in correlation to the methylation status of H19DMR.

xenograft WT and fetal kidney cells, which reported on a general activation of imprinted genes such as MEST, PEG3, NNAT, PEG10, and IGF2 (26). This study demonstrated a striking transcriptional upregulation of these genes in differentiated renal tissue after induction of ischemic injury. Thus, they postulated a similar repertoire of genes to be active 

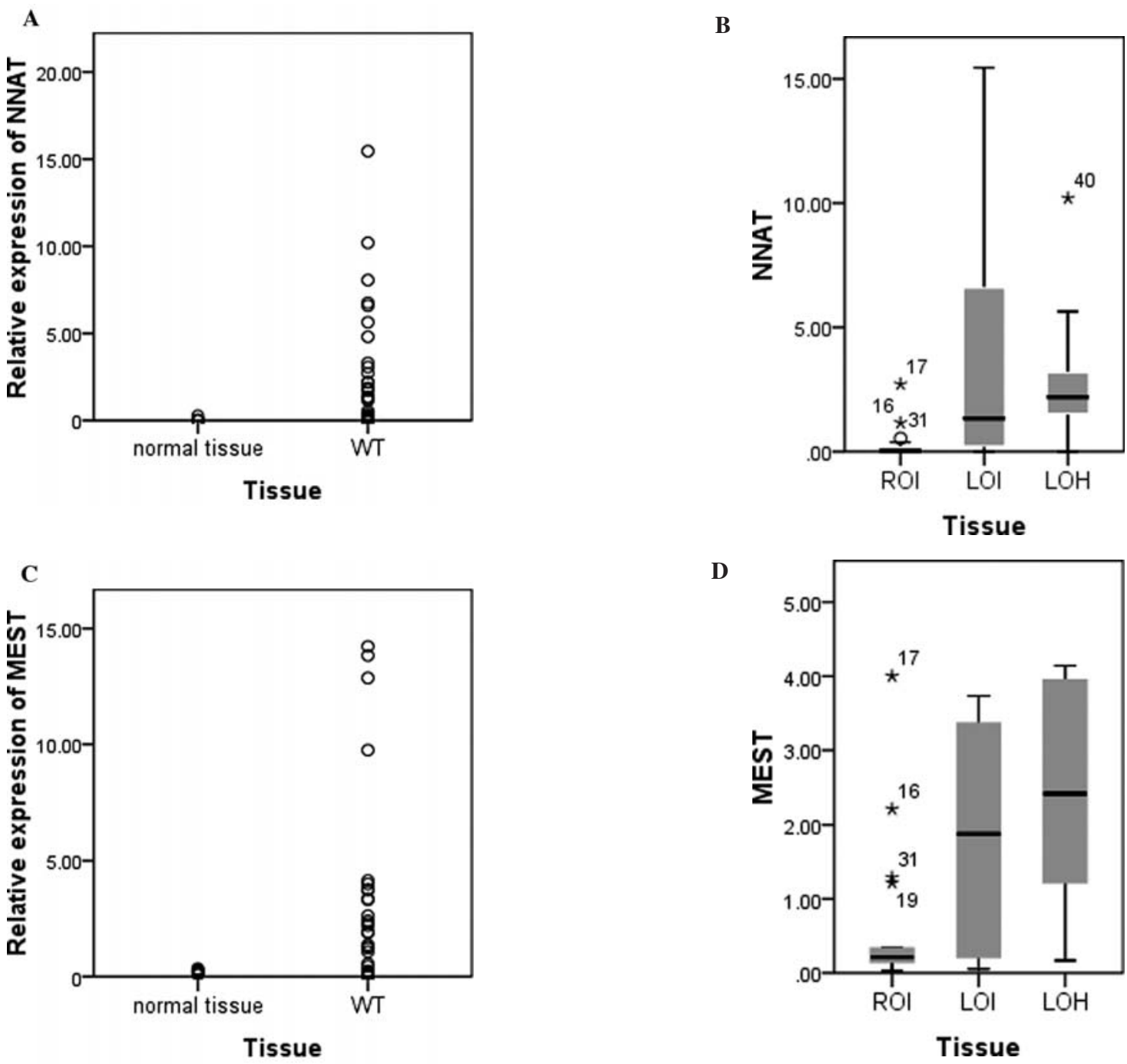

Figure 3. Expression analysis of the imprinted genes NNAT (A) and MEST (C) in normal renal and tumor tissues (WT), as determined by real-time PCR. Gene expression is calculated in relation to the housekeeping gene TBP. Correlation of gene expression and methylation status of $H 19 D M R$. Boxplots display distribution of TBP-normalized expression levels NNAT (B) and MEST (D) of tumor cases in correlation to the methylation status of H19DMR.

during the induction of repair mechanisms in injured renal tissue and the maintenance and progression of WTs. In summary, these findings suggest a general overexpression of imprinted genes in WTs by a yet unknown super-ordinated mechanism. Studies in other embryonal tumors such as hepatoblastoma and neuroblastoma assume these mechanisms as intrinsic for these tumors $(27,28)$.

To see whether widespread activation of imprinted genes in WTs depends on epigenetic changes, we analyzed the methylation status of $H 19 D M R$ and made correlations with the expression level of imprinted genes. H19DMR has been chosen, as deregulation of the IGF2/H19 cluster is a wellknown mechanism described in many embryonal cancers $(12,14,29)$. By using a quantitative real-time PCR-based method (14) we depicted that two-thirds of all WTs displayed alterations at this locus. These changes comprised 11 cases of LOI and another 11 cases of LOH. These data are consistent with a study by Fukuzawa et al (14), which showed a similar distribution of $\mathrm{LOI} / \mathrm{LOH}$ with same effects on IGF2 expression. In addition, LOI was detectable in two normal renal tissues of our study as well. However, it is well known that epigenetic changes are occasionally found in surrounding, histologically non-malignant tissues. Thus, these alterations seem to occur very early during tumorigenesis and might be responsible for malignant transformation of undifferentiated metanephric cells $(30,31)$. Moreover, by investigating the transcriptional behavior of different imprinted genes dependent of the H19DMR status, the level of IGF2 overexpression correlated with LOI or LOH. However, there are no differences with regard to IGF2 overexpression between LOI and LOH. Furthermore, we have seen an inverse correlation of IGF2 and H19. These findings propose that the regulation of the IGF2/H19 cluster is still efficient in WTs, with $H 19$ being transcriptionally impaired by $I G F 2$ overexpression.

Interestingly, we observed that LOI/LOH of H19DMR not only was associated with higher IGF2 levels, but significantly correlated with overexpression of MEST and NNAT, which play an important role in fetal development (20-23). Similar findings were published by Kohda et al who described a correlation of LOI at the IGF2/H19 locus and the MEST locus in case of lung adenocarcinomas (23). Thus, it might be 
speculated that genes involved in related physiological processes might be regulated by similar molecular mechanisms. However, our data show that whereas transcriptional activity of MEST and NNAT is associated with the H19DMR methylation status, genes of the DLK1/GTL2 locus are independently expressed of H19DMR. Even though the genes IGF2, NNAT, MEST, and DLK1 are involved in fetal development and/or cell differentiation $(20,21)$ and the regulation of the IGF2/H19 and the DLK1/GTL2 locus relies on comparable mechanisms with both DMR being methylated on the paternal allele (32), transcriptional activation of the DLK1/GTL2 locus is not correlated with the other genes. Altogether, these findings suggests that either transcriptional activity of imprinting clusters is regulated by different, yet unidentified superordinate regulatory elements or there are different epigenetic marks on the paternal chromosome representing the default state and enabling differential expression. The co-activation of IGF2, MEST and NNAT argues for the presence of the first scenario.

However, there is evidence to suggest that alterations in DMR methylation are specific for the $I G F 2 / H 19$ locus in case of WTs $(14,15,29)$. Nevertheless, our data broadens this concept by clearly documenting that transcriptional activation of imprinted genes is a common finding in WTs and imprinted genes are activated as functional units. In fact, there are some imprinted genes concomitantly overexpressed in tumors displaying LOI or LOH at the H19DMR that are involved in fetal development. Although we did not analyze the particular DMR of the NNAT, MEST or DLK1/GTL2 locus, our data indicate that defects in setting methylation marks in imprinting regions are not limited to one single locus $(I G F 2 / H 19)$, but seem to act throughout the genome. Consequently, activation of imprinted genes occurs in functional units and may be mediated by a superior regulatory mechanism, that is yet unknown.

\section{References}

1. Weihkopf T, Blettner M, Dantonello T, et al: Incidence and time trends of soft tissue sarcomas in German children 1985-2004: report from the population-based German Childhood Cancer Registry. Eur J Cancer 44: 432-440, 2008.

2. Li CM, Guo M, Borczuk A, et al: Gene expression in Wilms tumor mimics the earliest committed stage in the metanephric mesenchymal-epithelial transition. Am J Pathol 160: 2181-2190, 2002.

3. Hanahan D and Weinberg RA: The hallmarks of cancer. Cell 100: 57-70, 2000.

4. Wittmann S, Wunder C, Zirn B, et al: New prognostic markers revealed by evaluation of genes correlated with clinical parameters in Wilms tumors. Genes Chromosomes Cancer 47: 386-395, 2008.

5. Nakagawa H, Chadwick RB, Peltomaki P, Plass C, Nakamura Y and de La Chapelle A: Loss of imprinting of the insulin-like growth factor II gene occurs by biallelic methylation in a core region of $\mathrm{H} 19$-associated CTCF-binding sites in colorectal cancer. Proc Natl Acad Sci USA 98: 591-596, 2001.

6. Ohlsson R, Cui H, He L, et al: Mosaic allelic insulin-like growth factor 2 expression patterns reveal a link between Wilms' tumorigenesis and epigenetic heterogeneity. Cancer Res 59: 3889-3892, 1999.

7. Ulaner GA, Vu TH, Li T, et al: Loss of imprinting of IGF2 and $\mathrm{H} 19$ in osteosarcoma is accompanied by reciprocal methylation changes of a CTCF-binding site. Hum Mol Genet 12: 535-549, 2003.

8. Zhan S, Shapiro DN and Helman LJ: Loss of imprinting of IGF2 in Ewing's sarcoma. Oncogene 11: 2503-2507, 1995.
9. Jenuwein T and Allis CD: Translating the histone code. Science 293: 1074-1080, 2001.

10. Strahl BD and Allis CD: The language of covalent histone modifications. Nature 403: 41-45, 2000.

11. Burdge GC, Lillycrop KA, Phillips ES, Slater-Jefferies JL, Jackson AA and Hanson MA: Folic acid supplementation during the juvenile-pubertal period in rats modifies the phenotype and epigenotype induced by prenatal nutrition. J Nutr 139: 1054-1060, 2009.

12. Edwards CA and Ferguson-Smith AC: Mechanisms regulating imprinted genes in clusters. Curr Opin Cell Biol 19: 281-289, 2007.

13. Mummert SK, Lobanenkov VA and Feinberg AP: Association of chromosome arm $16 \mathrm{q}$ loss with loss of imprinting of insulinlike growth factor-II in Wilms tumor. Genes Chromosomes Cancer 43: 155-161, 2005.

14. Fukuzawa R, Breslow NE, Morison IM, et al: Epigenetic differences between Wilms' tumours in white and east-Asian children. Lancet 363: 446-451, 2004.

15. Fukuzawa R, Heathcott RW, Morison IM and Reeve AE: Imprinting, expression, and localisation of DLK1 in Wilms tumours. J Clin Pathol 58: 145-150, 2005.

16. de Kraker J, Graf N, van Tinteren H, et al: Reduction of postoperative chemotherapy in children with stage I intermediaterisk and anaplastic Wilms' tumour (SIOP 93-01 trial): a randomised controlled trial. Lancet 364: 1229-1235, 2004.

17. Pfaffl MW: A new mathematical model for relative quantification in real-time RT-PCR. Nucleic Acids Res 29: e45, 2001.

18. Lee MP, DeBaun MR, Mitsuya K, et al: Loss of imprinting of a paternally expressed transcript, with antisense orientation to KVLQT1, occurs frequently in Beckwith-Wiedemann syndrome and is independent of insulin-like growth factor II imprinting. Proc Natl Acad Sci USA 96: 5203-5208, 1999.

19. Scelfo RA, Schwienbacher C, Veronese A, et al: Loss of methylation at chromosome $11 \mathrm{p} 15.5$ is common in human adult tumors. Oncogene 21: 2564-2572, 2002.

20. Ansell PJ, Zhou Y, Schjeide BM, et al: Regulation of growth hormone expression by Delta-like protein 1 (Dlk1). Mol Cell Endocrinol 271: 55-63, 2007.

21. Sekita Y, Wagatsuma H, Nakamura K, et al: Role of retrotransposon-derived imprinted gene, Rtl1, in the feto-maternal interface of mouse placenta. Nat Genet 40: 243-248, 2008.

22. Wijnholds J, Chowdhury K, Wehr R and Gruss P: Segmentspecific expression of the neuronatin gene during early hindbrain development. Dev Biol 171: 73-84, 1995.

23. Kohda M, Hoshiya H, Katoh M, et al: Frequent loss of imprinting of IGF2 and MEST in lung adenocarcinoma. Mol Carcinog 31: 184-191, 2001.

24. Zhou Y, Zhong Y, Wang Y, et al: Activation of p53 by MEG3 non-coding RNA. J Biol Chem 282: 24731-24742, 2007.

25. Yoshimizu T, Miroglio A, Ripoche MA, et al: The H19 locus acts in vivo as a tumor suppressor. Proc Natl Acad Sci USA 105: 12417-12422, 2008.

26. Dekel B, Metsuyanim S, Schmidt-Ott KM, et al: Multiple imprinted and stemness genes provide a link between normal and tumor progenitor cells of the developing human kidney. Cancer Res 66: 6040-6049, 2006.

27. Astuti D, Latif F, Wagner K, et al: Epigenetic alteration at the DLK1-GTL2 imprinted domain in human neoplasia: analysis of neuroblastoma, phaeochromocytoma and Wilms' tumour. Br J Cancer 92: 1574-1580, 2005.

28. Honda S, Arai Y, Haruta M, et al: Loss of imprinting of IGF2 correlates with hypermethylation of the H19 differentially methylated region in hepatoblastoma. Br J Cancer 99: 1891-1899, 2008.

29. Bjornsson HT, Brown LJ, Fallin MD, et al: Epigenetic specificity of loss of imprinting of the IGF2 gene in Wilms tumors. J Natl Cancer Inst 99: 1270-1273, 2007.

30. Kaneda A and Feinberg AP: Loss of imprinting of IGF2: a common epigenetic modifier of intestinal tumor risk. Cancer Res 65: 11236-11240, 2005.

31. Ravenel JD, Broman KW, Perlman EJ, et al: Loss of imprinting of insulin-like growth factor-II (IGF2) gene in distinguishing specific biologic subtypes of Wilms tumor. J Natl Cancer Inst 93: 1698-1703, 2001 .

32. Lin SP, Youngson N, Takada S, et al: Asymmetric regulation of imprinting on the maternal and paternal chromosomes at the Dlk1-Gtl2 imprinted cluster on mouse chromosome 12. Nat Genet 35: 97-102, 2003. 